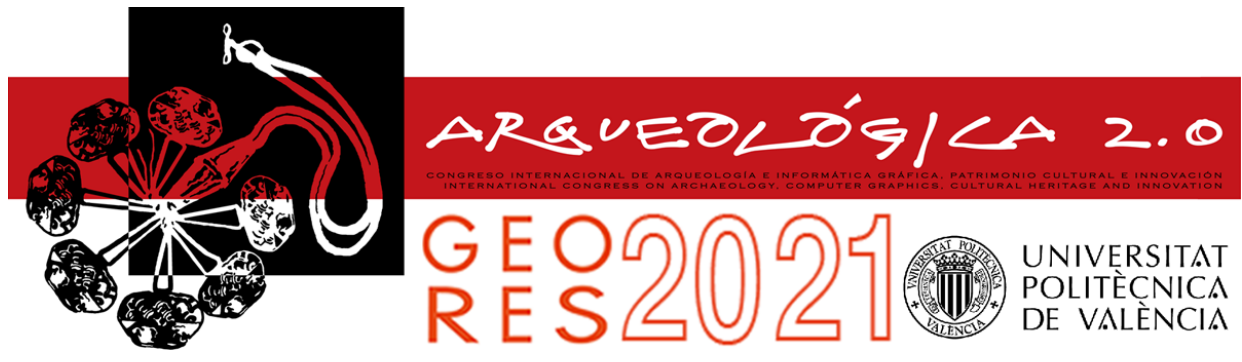

\title{
READING INTEGRITY IN THE LANDSCAPE: METHODS' COMPARISON ON TICINO AREA
}

\author{
Paola Branduinia ${ }^{a}$, Mattia Previtalia ${ }^{,}$, Eugenia Spinellia, Marco Tagliabue ${ }^{b}$ \\ ${ }^{a}$ Department of Architecture, Built Environment and Construction Engineering, Politecnico di Milano, Via Ponzio 31, 20133 Milan, Italy. \\ paola.branduini@polimi.it; mattia.previtali@polimi.it; eug.spinelli@gmail.com \\ b GPSBrianza, Parco del Ticino, Italy. mark.taglia@gmail.com
}

\begin{abstract}
:
The landscape is the system of both tangible and intangible heritage. A key element to evaluate a landscape is its integrity intended as the wholeness and intactness of natural and/or cultural heritage. The problem of identifying the integrity of a landscape is twofold: on one side it is necessary to identify the element that determines the intactness of a landscape and on the other side the methodology to study and quantify the integrity. Different methodologies have been developed in the literature to assess and measure landscape integrity: some of them are more quantitative, while others are more qualitative. This paper presents two different methods for landscape integrity evaluation: the Valutazione Storico Ambientale (VASA) and the Landscape System Historical Analysis (LaHSA) one. The comparison of the two methodologies is carried out in a portion of the Ticino river (North Italy) and more specifically in the municipality of Morimondo. The two methods are compared considering a set of elements taking into account both the understanding of tangible and intangible permanencies and data accessibility/accuracy to carry out the analysis.
\end{abstract}

Keywords: VASA methodology, historical rural landscape, integrity, historical analysis

\section{Introduction}

The landscape is a tangible and intangible heritage (ICOMOS, 2017; Scazzosi, 2018a). This connection is part of UNESCO's broader reflections on integrity that lead to a cultural landscape to be included in the World Heritage List (UNESCO, 1972). In Article 88 of the Guidelines for the implementation of the World Heritage Convention (2011), integrity is defined as "a measure of the wholeness and intactness of the natural and / or cultural heritage and its attributes". It "includes all elements necessary to express its outstanding universal value" and it has to have an "adequate size to ensure the complete representation of the features and processes which convey the property's significance". The attributes to assess integrity are indicated in the Operational Guidelines and are related to tangible permanence, namely form and design, material and substance, location and settings, and intangible permanence, namely tradition, techniques, language, spirit and feeling.

Therefore, in order to assess the integrity of a landscape, the question is twofold: on one hand, we should consider which elements and at which scale they should be taken into account, on the other hand, we should define which method/approach to use to evaluate the permanence of the previously listed attributes of the landscape. In this context, the availability of digital tools (Yang \& Han, 2020) can be of primary importance to evaluate, quantify and report the landscape integrity. In particular, this paper would like to offer a reflection on the evaluation of historical permanencies in a landscape through two different approaches relying on GIS tools.

We also assume to overcome the interpretation of the landscape reading as a simple sum of different elements and we move towards the concept of landscape system: "the landscape as a system comprehends its social and functional organization. It is not possible to explain the landscape system by reading its components separately. " (Scazzosi, 2018b; Branduini, Laviscio, L'Erario, \& Toso, 2019; Mitchell, 2008).

Talking about historical remains, the emerging problem is which historical documents and in particular maps and land use registers (mainly land registry) are useful and digitally available as fundamental references to assess integrity. Historical analysis requires not only map and registry availability but also their effective utilization. In particular, maps should be digitalized and georeferenced. Direct georeferencing, intended as a transformation between two coordinate systems where transformation parameters are known, is not always feasible and/or desirable. This may result in the need for georeferencing large set historical maps (Brovelli \& Minghini, 2012). 
Methodologies relying on historical analysis for reading and interpreting the landscape integrity are based both on mapping land use surfaces, tree or wall lines and buildings, attributing indices (quantitative method), and interpreting the relations among the landscape permanencies (qualitative method). Indeed, Gullino \& Larcher (2013) in their discussion about methodologies to evaluate integrity, state that "the scientific community agrees with a multidisciplinary and integrated approach to integrity, not one based on pure historical interpretation". Moreover, Scazzosi (2004) explains that the integrity concept is not limited to the definition, but it also relates to theoretical, methodological, and experimental work at different levels.

The purpose of this contribution is to compare two of these methodologies, one more quantitative, the Valutazione Storico Ambientale (VASA), the other more qualitative, the Landscape System Historical analysis (LASHA), both used to assess integrity on the Italian territory. In particular, the purpose of the comparison is to understand the pros and cons of each one of them and evaluate the two methodologies on the basis of contents and technical-practical criteria.

In order to carry out the presented comparison data availability is a key element. Indeed, both methodologies analyzed in this paper are taking advantage of historical maps and land register data available in archives. Availability of those data is a key issue of both presented methods.

\subsection{Case study}

We selected to conduct the study on Ticino Valley because part of the authors' team is working on the candidature of water meadows landscape along the Ticino valley for the Historical landscape National Register, promoted by the Ministry of Agricultural, Food and Forestry Policies. The methodology requested by the Ministry is the VASA, and during the application of the methodology, we encountered some problematic issues concerning data source selection and interpretation, notably with regards to the meadow identification in the GAI map requested. In fact, tree cultivation, like vineyards or olive trees, are easier to be identified in GAI maps; conversely, the distinction between arable land and meadows is really hard to perform. The two methodologies have been applied on a portion within the Milan district, with two macrozones divisible in the area within the Ticino river valley, and a second one outside to underline the differences between the two neighbouring regions. The two regions are so different in the land uses dynamics.

\section{Material and method}

\subsection{Tables VASA methodology}

The VASA methodology was born in the early 2000s. It takes up the Historical and Cultural Evaluation Approach (HCEA), conceived and used by the Department of Forest Sciences and Technologies of the University of Florence to monitor the state of the Tuscan landscape (Agnoletti, 2006). Today it is proposed in the National Register of Historic Rural Landscapes to understand the evolution of the landscape and to evaluate which areas meet the criteria issued by the Ministry of Agricultural, Food and
Forestry Policies in order to become part of the Register. In fact, the VASA analysis is regulated by strict ministerial directives.

The VASA evaluates the landscape with a historical approach. It aims to understand the evolutionary dynamics of the territory; to estimate the state of the landscape through the use of indices deriving from landscape ecology and to produce assessments of integrity, importance and vulnerability already used for the UNESCO World Heritage List (Agnoletti, 2007). Furthermore, it aims to consider and preserve the habitats deriving from human influence. For this purpose, it focuses on the land uses, considered as the basic tiles of the mosaic that forms the landscape.

The methodology is based on the photo interpretation: two aerial photos belonging to two different eras are analyzed and compared. The first is generally taken from the 1954 GAl flight, the last image of the whole Italian territory before the transformations that took place after the Second World War. The second is from the current era.

Once the images have been geo-referenced a land cover map is produced for each historical period in a GIS environment. The minimum mappable unit is $500 \mathrm{~m} 2$. In the case of particularly fragmented landscapes, a minimum unit of $250 \mathrm{~m} 2$ is accepted. Linear and point elements can be identified for further analysis, which may include: linear or scattered trees: hedges; monumental trees; plants showing traces of traditional cutting techniques; artifacts of historical rural construction; elements pertaining to historical, architectural, archaeological heritage; land arrangements such as terracing, verges (Agnoletti \& Tempesta, 2016). So, we proceed with the comparison of the data collected to know the evolutionary dynamics of the specific area. In particular, by overlapping the layers relating to land uses, a third information layer is obtained in which the portions of the territory are classified according to the following terms:

- Built up: loss of forests, crops or pastures, replaced by urbanized areas.

- Deforestation: loss of forested land, replaced by cultivated areas or pastures.

- Extensification: transition from intensive to extensive cultivation.

- Forestation: loss of cultivated areas or pastures, replaced by shrub or tree formations.

- Intensification: transition from extensive to intensive cultivation.

- Stable: land use has remained constant (Agnoletti, 2006).

To recognize these cases is facilitated by the creation of the Cross Tabulation, a graph that facilitates the choice of evolutionary dynamics for each change in land use that occurs in the area over time. Starting from the crosstabulation and related data, using a given formula, it is calculated the historical index that evaluates the risk of disappearance for each agricultural practice. Lastly, following the parameters provided by MIPAAF (Ministry of Agricultural, Food and Forestry Policies), the class of integrity to which the landscape under examination belongs is established. To complete the analysis, the 
following files are required: cartography that indicates the linear and punctual elements present in the landscape; the calculation and comparison of data relating to the fragmentation and extension of land uses; the charts and histograms necessary to explain each cartography data (Reterurale, 2021).

\subsection{LaSHA methodology}

The LASHA methodology is a way of interpreting the landscape, developed by research activities of the PaRID laboratory at the Politecnico di Milano: it is applied to different scales, from the territorial scale (city-country ratio) to the farm scale (farm, buildings and fields) and allows good control of the project in the landscape. It is based on the interpretation of the landscape as a system of material permanencies (waters, roads, rural buildings, vegetation - woods, rows, hedges - use of agricultural land and division of fields) linked by immaterial relationships (economic, social, cultural), evolving through time. This interpretation is in line with the studies of Marc Bloch and Fernand Braudel on material culture and with the Unesco concept of evolutionary landscape (Scazzosi, 2011). The "reading by systems" methodology is applied in order to understand the historical evolution of places: firstly, a diachronic analysis is done with the aim to read the transformations at the different historical thresholds, secondly a synchronic analysis is prepared in order to understand the tangible and intangible permanencies (of elements and relationships) still present today. This last interpretation responds to the need to understand only material and meaning pieces of evidence, avoiding the possibility of reconstructing elements that have no material permanence, in compliance with the principles of conservation (from the Venice Restoration Charter, 1964 to the of Krakow of 2000). Developed in Lombardy, the diachronic study analyzes the historical cadastral maps to depict an image "of the historical landscape at each century. Normally, the period from the $18^{\text {th }}$ century to the present is analyzed. In Lombardy for each period are available the respective materials that will be discussed in paragraph 2.3: for the '700 is used the Catasto Teresiano, for the ' 800 the cadastre Lombardo Veneto, for the ' 900 the IGM maps dated 1930 and for the current landcover map (DUSAF).

The cadastral maps are providing not only a detailed description of the landscape structure (roads, channels, etc.) but also a rich description of the different land uses and cultivation (e.g., water meadows, crop fields, etc.). Small scale maps (1:30.000) were used to analyse the structure of the landscape at a territorial scale providing a larger picture of the structure of the territory in terms of connection (road and water) as well as a general identification of the land uses. On the different maps, waters channel, roads, rural buildings, vegetation woods, rows, hedges - use of agricultural land and division of parcels are traced, and to each land use we assigned a color that can be associated with reality (so the cereal fields will be shades of yellow, the meadows green, dark green woods).

In particular, once historical maps are georeferenced the different land parcels, roads and water network are digitized in a GIS environment. The information concerning the land uses are derived from data coming from land registry archives. A research in the archive was carried out to link the land uses and the land parcels. The land use data are stored in a shapefile characterized with the following attribute table: "ID" identifying the parcel identifier reported in the maps, "Land use" reporting the land uses reported in the and registry archive and "toponym" reporting (if present) the toponym of the land parcel. Water networks are digitized making a specific distinction among the different levels of the hydrographic network (e.g., main river, secondary rivers, channels , "rogge", etc.). A similar distinction is done for the road network: main roads, secondary roads, pathways, etc. In this way, the diachronic maps belonging to the different historical periods chosen are obtained. The analysis of the results and their comparison takes place de visu. The analysis of the results and their comparison takes place de visu in order to understand which portions of the territory derive from which historical periods. The synchronic map is constructed by reporting on the current cartography (for example Google map or regional technical map) the permanences of previous epochs, attributing a colour to each historical period (usually decreasing from red to yellow) and attributing different graphic signs to the different elements of the landscape. The synchronic map allows you to know for each element of the landscape still present today when it was created. The identification of permanencies is done according to the criteria shown in Table 1.

Table 1: Criteria for identifying permanencies.

\begin{tabular}{c|c} 
Land use & Permanence \\
\hline Riparian woodlan & Forest \\
Futting forest & \\
Mixed coppic & \\
\hline Irrigated meadow & Pasture and meadow \\
Wet meadow & \\
Pasture & \\
\hline Arable land & Arable land \\
Arable land with vineyar & \\
\hline Chestnuts wood & Trees crop \\
\hline Trees crop & \\
\hline Irigated arable land & Irrigated arable land \\
\hline Rice field & Rice field \\
\hline Path & Path \\
\hline Water body & Water body \\
\hline
\end{tabular}

The interpretation of the permanences could be completed by the creation of a so-called "bloc-diagram" or axonometric section which, through the addition of textual labels, allows to explain the underlying economic and functional relationships between the cultivations and rural buildings: it can be created for each historical threshold, as well as for the current state (Scazzosi \& Branduini, 2014).

\subsection{Materials}

The two methods compared in this paper differ significantly for the materials used for the analysis of landscape integrity. 
The VASA methodology relies on the comparison of two different landuse maps. Generally, landuse maps are derived from photointerpretation of the photogrammetric aerial survey with panchromatic film black and white collected by the Istituto Geografico Militare Italiano (IGM) acquired in 1954/1955 by a specific group named "Gruppo Aereo Italiano" (G.A.I.). For this reason, the dataset is generally named as 1954 GAl Flight. The dataset has an average frame scale ranging from $1: 45,000$ in mountainous areas and 1:33,000 in lowland areas. The images were digitized with a scanning quality ranging between from 800 to 2500 DPI. Orthophotos derived from the 1954 GAI Flight are available at National and Regional level as already georeferenced products as well as a layer providing the land use derived from photointerpretation. The photointerpretation of the 1954 GAl Flight is a challenging task since there is no information about the date of the frame shoot used for the G.A.I mosaic, so it's not possible to associate a detailed specification of the kind of agricultural crop or lawn. For this reason, in the presented work we are using a different dataset. In particular, we used IGM maps at 1:25000 scale realized in the ' 30 s. The main advantages of using this dataset are: i) a larger scale compared to the 1954 GAI Flight, ii) a higher level of detail in the definition of land used with respect to those that can be derived from the interpretation of the 1954 GAl Flight, iii) IGM '30s maps were realized before the big urbanistic transformations that involved Italy after Second World War. The second data set used for the VASA analysis is the official land use map of the Lombardy region (named DUSAF) realized in 2018. DUSAF map was complemented by an in-situ survey to verify and possibly correct the land use map. Due to its original error, we used the corrected version of DUSAF for analysis. Verification focused on the Valley area, the nearest to the Ticino river. However, a more complete data assessment should be done also on the entire study area.

The LaSHA methodology relies on the comparison of several land use maps (one per century) to create synchronic and diachronic maps. In this work the map analyzed are the following ones:

- The "Teresian Cadastre" (1722) wanted by the Empress Maria Theresa of Austria to know and quantify value of the land on which she ruled, drawn up on a scale of approximately 1:2.000.

- The 1865 so-called "Lombardo Veneto Cadastre" commissioned by Charles VI, always on an approximate scale. Both land registers allow accurate mapping of land use parcel by parcel thanks to the indications reported on the map or in associated registers.

- IGM maps drawn up at a scale of 1: 10.000 or 1: 25.000 around the 1930s and subsequent updates. The latter, even if at a larger scale, are very accurate and the land uses are mapped as well as the presence of trees.

- For the current situation the regional technical map and landcover map (DUSAF) are used, cross checked with IGM maps and with the aerial photo.
The first step of the LaSHA method is the georeferencing of the historical maps of the Therian and the Lombardo Veneto cadaster (IGM maps and DUSAF are already georeferenced). The georeferencing is carried out without known parameters by (i) using as reference data set the current cartography, (ii) finding corresponding points, and (iii) applying an affine transformation method. In particular, the georeferencing of historical maps was carried out in a two-step way: (i) georeferencing of historical maps to a contemporary coordinate system and (ii) mosaicking of the individual map sheets into a unique map (Previtali \& Latre, 2018). To guarantee a good overlap between consecutive sheets we georeferenced each image separately first and then we used boundary points to stitch them together in a final map. The accuracy of maps georeferencing is mainly affected by two different aspects: (i) the period of the map production and (ii) the nominal scale of the original map. In the presented work cadastral maps of different epochs (XVIII and XIX centuries) are used. Both map series were designed for the scale 1:2000. However, the XVIII century maps georeferencing can be considered compatible for the scale $1: 5.000-1: 10.000$ (this is mainly due to the difficulty in determining corresponding points in agricultural areas), while the XVIII century maps are compatible for the scale 1:2.000-1:5.000. As previously highlighted one of the most important aspects concerning LaSHA methodology is the georeferencing of the historical maps. Georeferencing is carried out in a QGIS environment by using the Georeferencer Plugin. Georeferencing is performed without known parameters using the current cartography as the reference dataset, finding minimum of four corresponding GCP points, and applying a polynomial transformation method. Finally, an evaluation of the georeferencing accuracy was carried out by considering a set of Ground Control Points (GCPs) and evaluating the difference between their position in the georeferenced historical cadastre and their actual position. The results of this analysis are summarized in Table 2.

Table 2: Analysis of historic map georeferencing results.

\begin{tabular}{c|c|c|c} 
Cadastre & $\begin{array}{c}\text { Mean GCP } \\
\text { distance } \\
(m)\end{array}$ & $\begin{array}{c}25 \% \\
\text { percentile } \\
(m)\end{array}$ & $\begin{array}{c}75 \% \\
\text { percentile } \\
(m)\end{array}$ \\
\hline $\begin{array}{c}\text { Teresian } \\
\text { Cadastre 1722 }\end{array}$ & 10 & 8 & 19 \\
$\begin{array}{c}\text { Lombardo } \\
\text { Veneto } \\
\text { Cadastre 1865 }\end{array}$ & 8 & 5 & 17
\end{tabular}

\subsection{Criteria of comparison}

The two methodologies are compared following criteria that concern the ease to understand permanencies and the accessibility and availability of digital data.

Thus, the criteria selected for detecting permenencies are:

- Ease to identify tangible permanencies: form and design, material and substance, location and settings.

- Ease to recognise intangible permanencies: tradition, techniques, language, spirit and feelings. 
- Clarity in graphical representation: it comprehends colour selection, graphical signs and symbols associated to elements.

The criteria selected to assess availability and accessibility of data are:

- Data availability: it refers to the difficulty to access the basic data to be analyzed.

- Data interpretation facility: on the trial of extrapolating information from the basic data.

- Need for data integration: it relates to the need to acquire additional data to complete the analysis.

- Quality (type) and quantity (number) of analyzed data (as polygons and as linear elements).

- Data analysis complexity: it refers to the difficulty of processing data and generating information.

- Execution times.

\section{Results}

\subsection{The VASA analysis applied to Ticino - Morimondo case study}

The VASA methodology provides five main results:

- Maps that identify land uses (Fig. 1) and rows of trees (Fig. 2) in the different periods.

- Tables and histograms (Fig. 3) that show the percentage of different land uses within the analyzed area and it's strictly linked to the previous maps.

- A map that shows how the landscape changes in the two different periods (Fig. 4a). Pink shapes identify permanences, the yellows ones the intensification of crops kind, for example. the switch from meadows to generic arable field.

- Cross-tabulation tables and pie charts (Fig. 5) where identical or similar land uses have pink colour.

- Two indexes: the first one (Fig. 6) shows how much the landscape is fragmented, with the number of patches and their extension. It's useful to understand how much nowadays fields grow in extension for companies' needs. The second one is the Historic Index (HI) that is a value associated with different kinds of crops that show the land uses that don't change from time to time (Fig. 7). In the map (Fig. 8) remain just the fields which have exactly the same value in the two years of analysis.

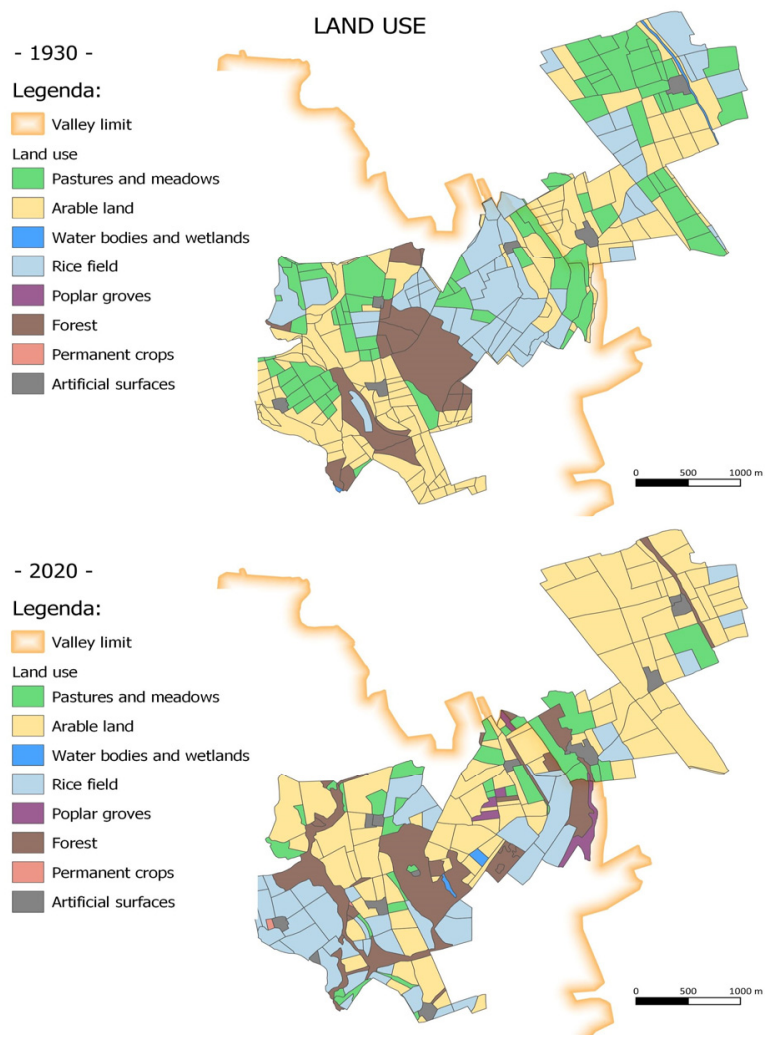

Figure 1: Land use maps of 1930 and 2020.

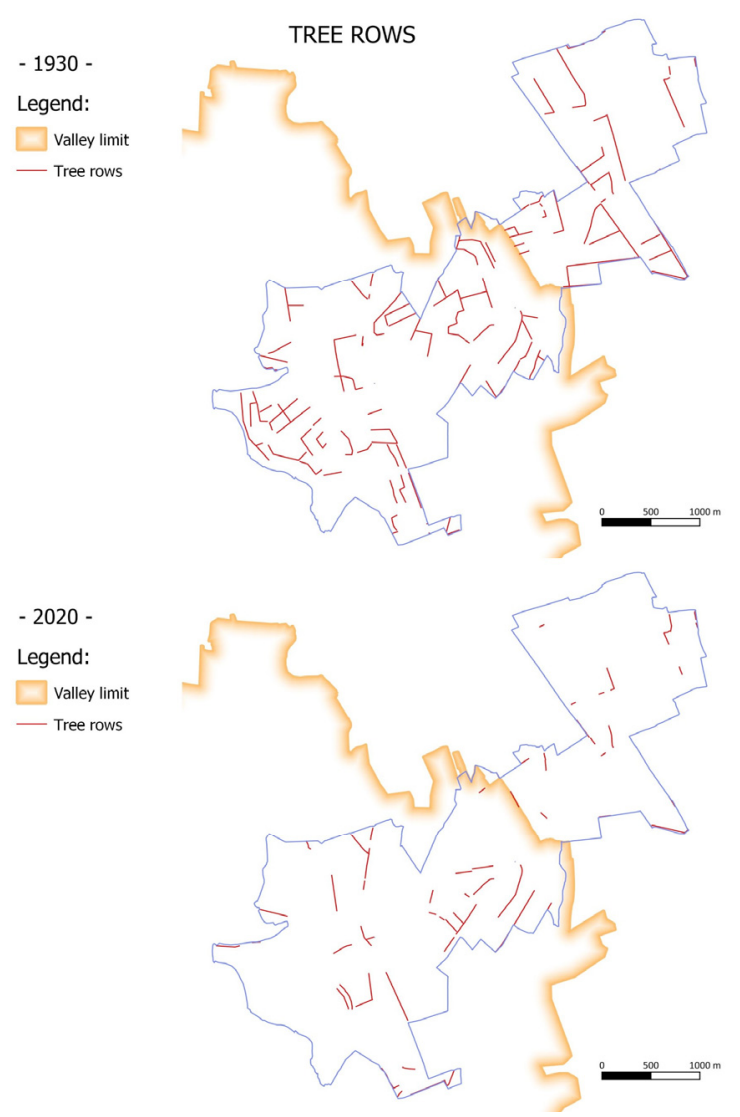

Figure 2: Rows of trees maps of 1930 and 2020. 

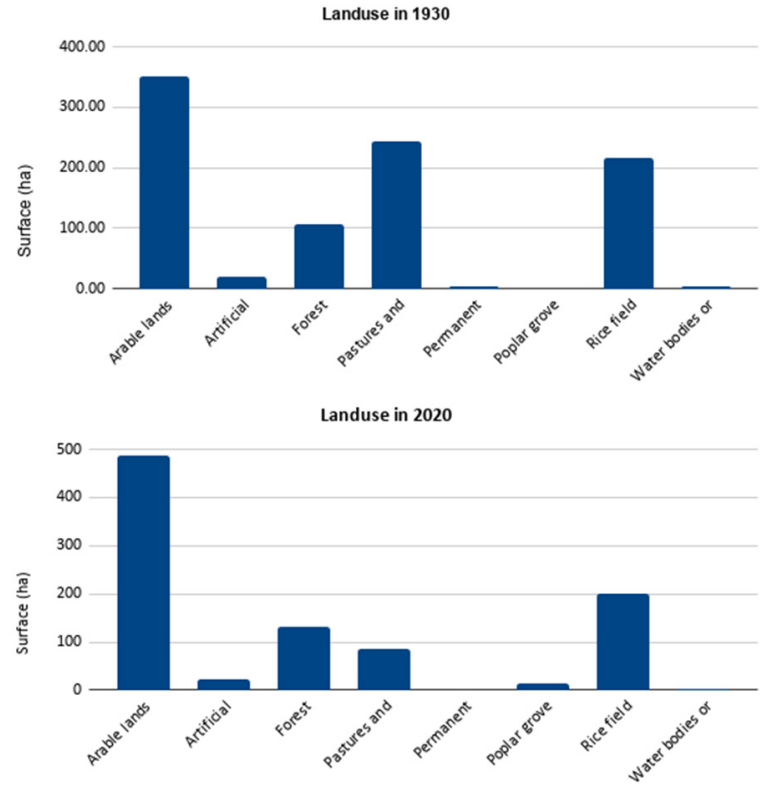

Figure 3: Land use histogram of 1930 and 2020.

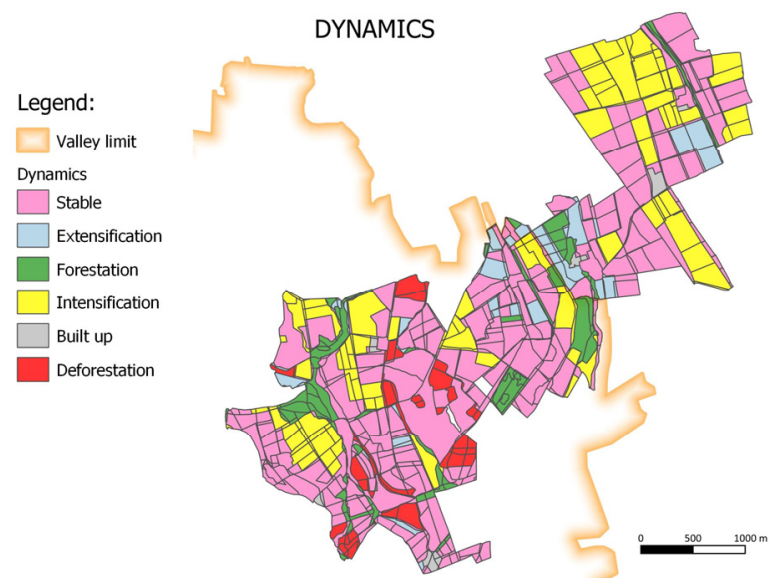

Figure 4: The map of land use changes between 1930 and 2020.

\subsection{The LaSHA analysis applied to Ticino - Morimondo case study}

The analysis shows a decrease in land uses, in particular the subsequent disappearance of promiscuous crops and woodland used for logging that have been rarefied since the $18^{\text {th }}$ century. Specifically, we note that forests underwent a strong decrease between ' 700 and ' 900 with a slight increase in 2020 . The canalizations have seen a thickening in the ' 800 and ' 900 and then remain stable, the same happens for the paths. Grazing disappears between ' 800 and ' 900 . While already in the ' 900 there is a decrease of irrigated arable land in favour of nonirrigated and in general a prevalence of rice fields on arable land.

Finally, between 1900 and 2020 there is a reduction in meadows and pastures. As far as permanence is concerned, it can be seen that the woodland visible today was already present in the 1700 s, while the percentage of irrigated and non-irrigated arable land datable to the 1700 s is very small. Most of the fields originate in the 1900s. There are few portions of land where land uses can be traced back to the 1800 s. On the other hand, we find a large part of irrigated and non-irrigated arable land dating back to the 1900 s and a good part of the rice fields. Thanks to the analysis carried out, we have been able to identify the periods of belonging of the individual portions of the territory and to define which of the canals and paths in the area can be traced back to which historical periods, highlighting also in this case the presence of traces in the landscape dating back to the ' 700 .

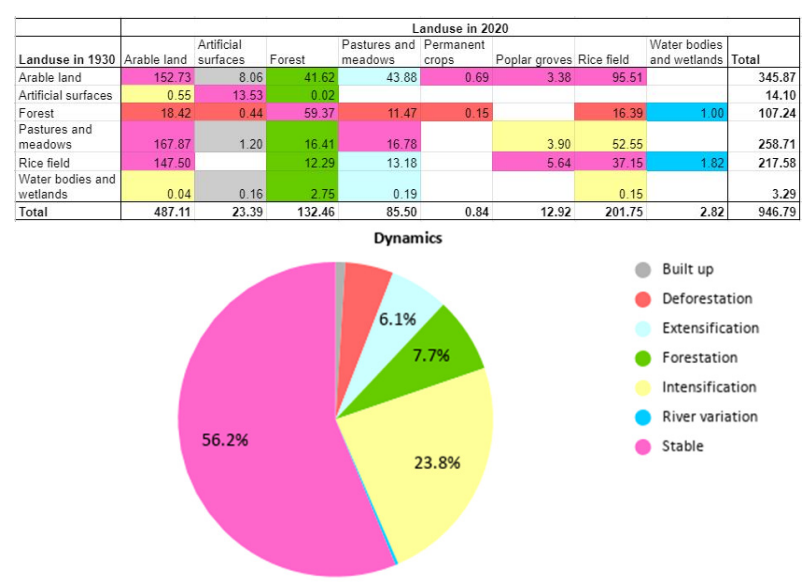

(a)

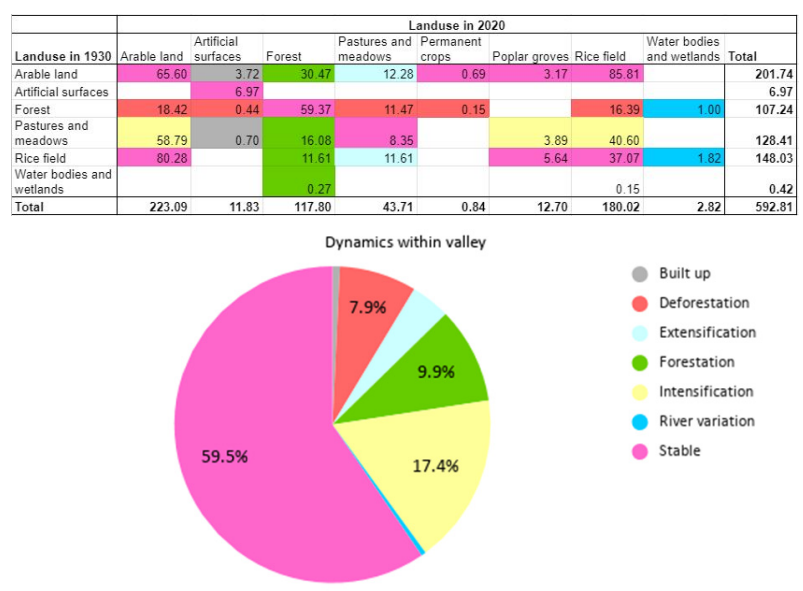

(b)

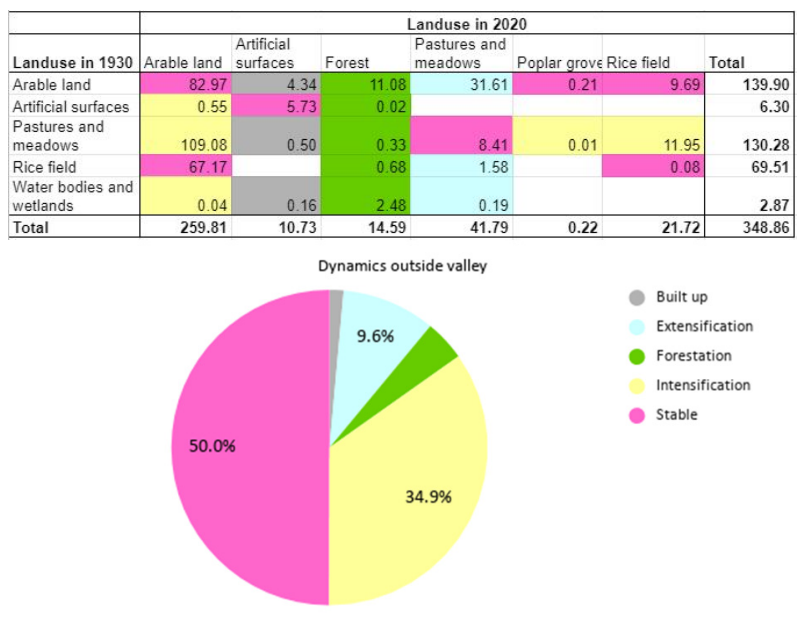

(c)

Figure 5: Cross-tabulation table and pie chart show the percentage of the changes, referred to the entire area (a), and details within (b) and outside (c) the Ticino Valley. 


\begin{tabular}{l|r|r} 
& 1930 & $\mathbf{2 0 2 0}$ \\
\hline Number of patch & 2227 & 2239 \\
\hline Medium surface (ha) & 3.16 & 4.32 \\
\hline Agricoltural medium surfa & 3.00 & 4.38 \\
\hline Number of landuses & 6 & 8
\end{tabular}

Figure 6: Historical index map showing the persistence of historical land uses.

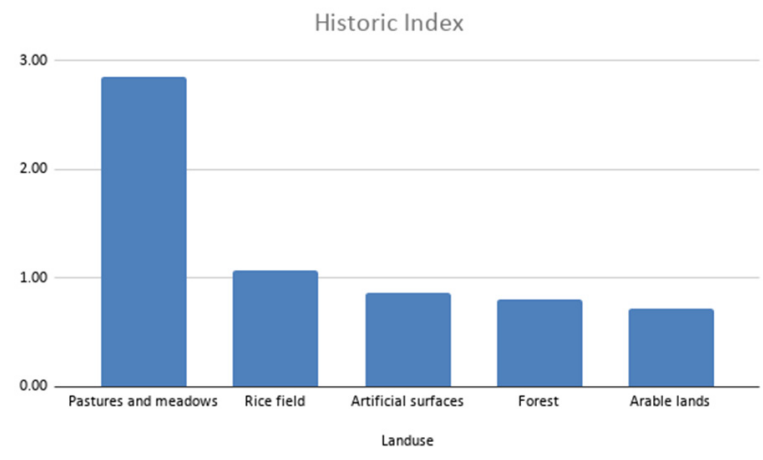

Figure 7: Histogram with historic index sorted decrescent.

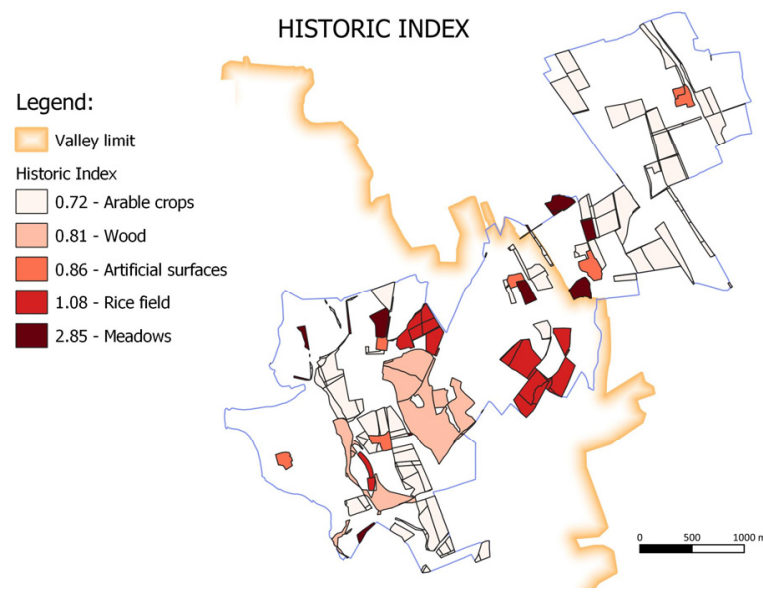

Figure 8: Historical index map showing the persistence of historical land uses.

Results of the proposed LaSHA analysis for the same area studied with the VASA are presented in Figures 912. Here the diachronic Landscape analysis is carried out for the following historical phases: i) 1722 - Theresian Cadastre, ii) 1866 - Lombardo Veneto Cadastre, iii) 1930 - Tavole IGM and iv) 2018- CTR Lombardia.

As can be observed (Fig. 11) the diachronic Landscape analysis for the same time period previously discussed is carried out. Figure 13 presents also an example of Synchronic Landscape Analysis: the permanences are represented on a current map attributing a colour to permanences for each historical period.
XVIII century - Teresian Cadastre 1722

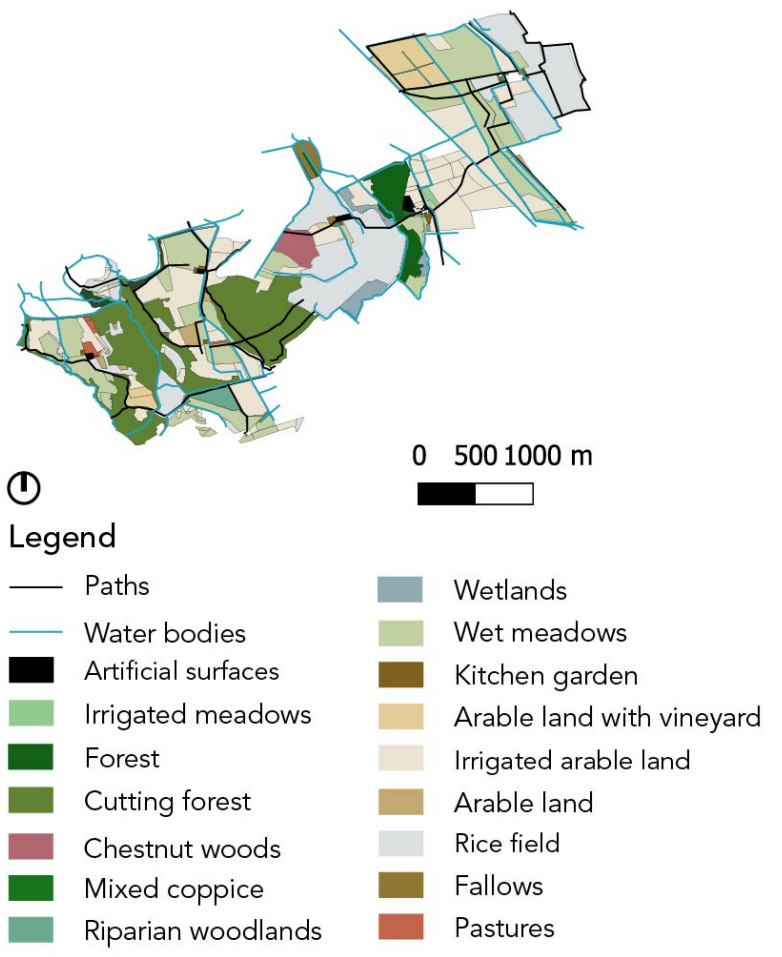

Figure 9: Diachronic Landscape Analysis: 1722 - Theresian Cadastre.

XIX century - Lombardo Veneto Cadastre 1866

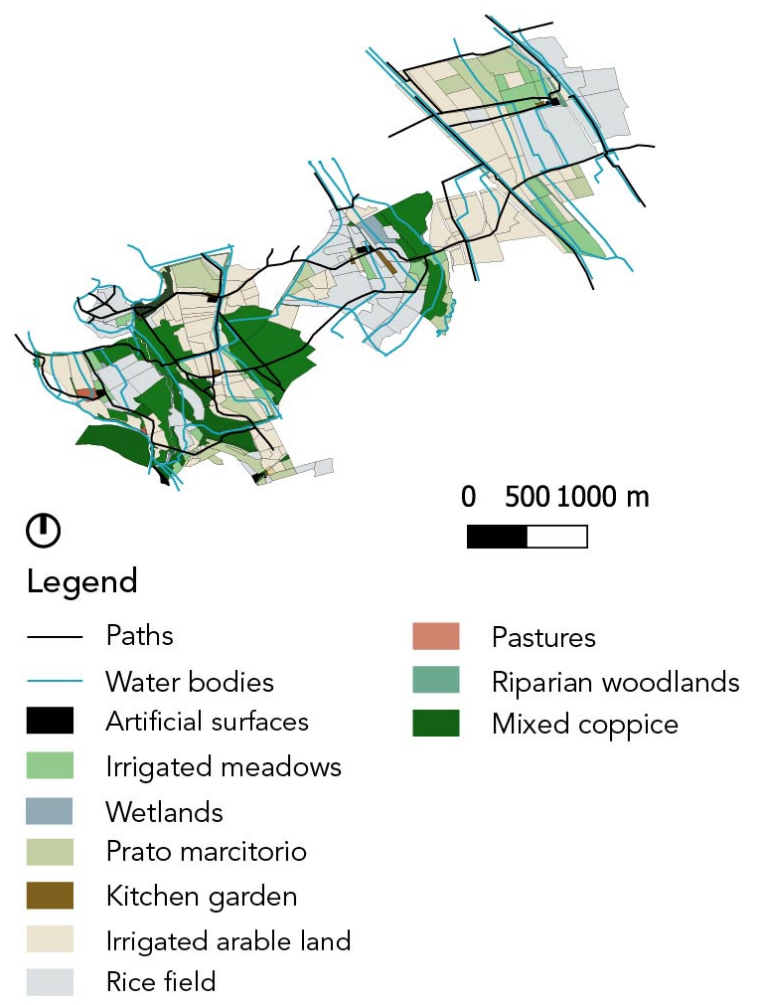

Figure 10: Diachronic Landscape Analysis: 1866 - Lombardo Veneto Cadastre. 


\section{XX century - IGM 1930}

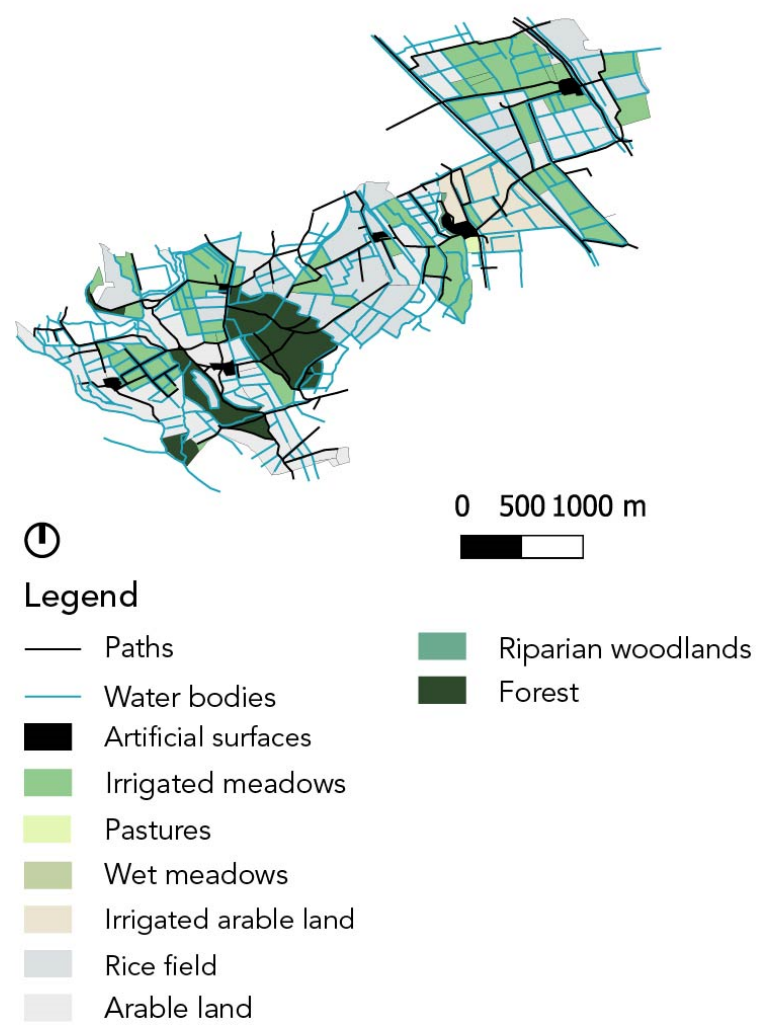

Figure 11: Diachronic Landscape Analysis: 1930 - Tavole IGM.

Current situation - CTR Lombardia 2020

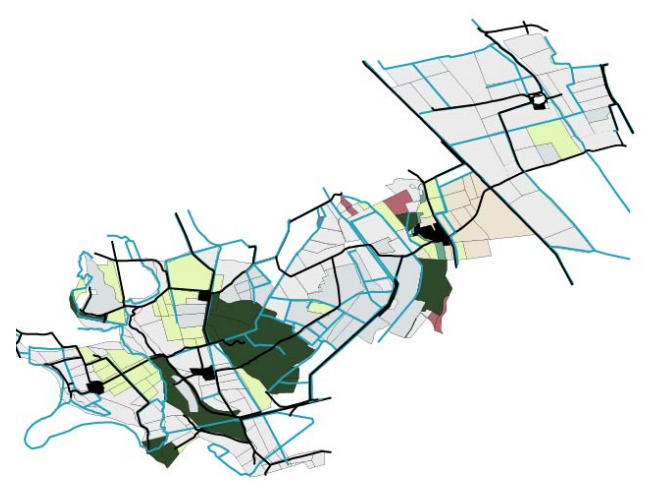

(1)

$0 \quad 5001000 \mathrm{~m}$

Legend

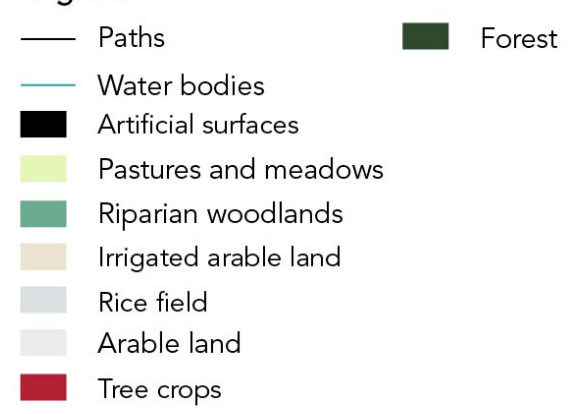

Figure 12: Diachronic Landscape Analysis: 2018- CTR Lombardia.

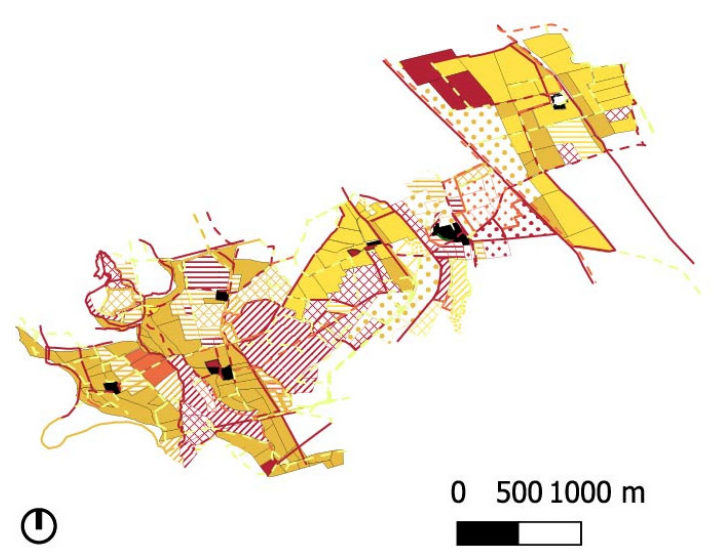

Legend

\begin{tabular}{|c|c|c|}
\hline$<\mathrm{XVIII}$ century & \multicolumn{2}{|c|}{$<\mathrm{XIX}$ century } \\
\hline --- Paths & --- & Paths \\
\hline Water bodies & 一 & Water bodies \\
\hline Irrigated arable land & 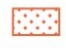 & Irrigated arable land \\
\hline Arable land & & Arable land \\
\hline Rice field & $x$ & Rice field \\
\hline Forest & एII & Forest \\
\hline Tree crops & $\because$ & Tree crops \\
\hline Pastures and meadows & 昰 & Pastures and meadows \\
\hline Artificial surfaces & & Artificial surfaces \\
\hline
\end{tabular}

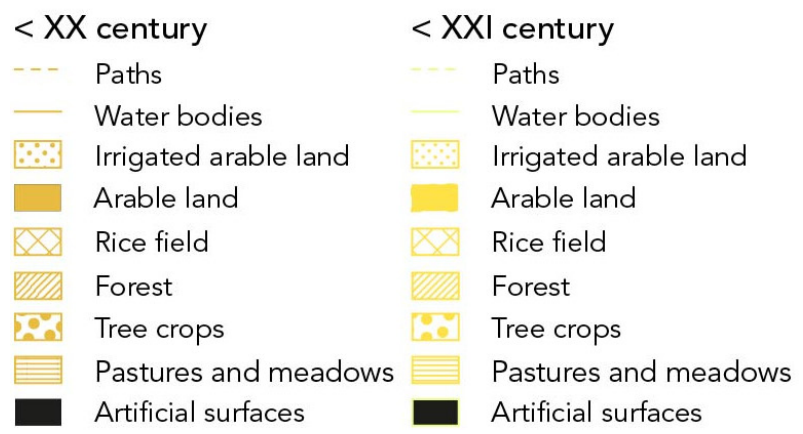

Figure 13: Synchronic Landscape Analysis.

\subsection{Results analysis}

VASA analysis offers good results with its construction of indexes and maps, thanks to this, it's easy to understand how much the landscape and the land use change. It's a quantitative analysis. But It's probably more useful by cropping the analysis area, to better understand dynamics and to make a more accurate and specific evaluation about. Doing this, it's clear how much the dynamics of land use tend to the intensification outside the Ticino Valley. It's easy to see how many crop fields (yellow shapes) replace pastures and meadows (in green), especially outside the Ticino Valley in the NorthEast (orange line) (Fig. 1). Even another important landscape element, rows of trees (Fig. 2), progressively disappear in the years outside the valley. Differences between the two areas emerge even with the next step of VASA: cross-tabulation tables and pie charts (Fig. 5) show in numbers and part how much the crops change. As shown in Figures $5 b$ and $5 c$, the percentage of fields that don't change land uses grows within the Ticino Valley, and fields converted for intensification use grow 
massively outside the valley. We need to make attention about pie charts: they should be illusory, especially for small areas; extensification changes (light blue) outside the valley have a relatively high percentage but it's referred to a real small area where crops kind change.

\section{Discussions}

\subsection{Permanencies' comprehension}

The LASHA methodology analyzes permanencies on a longer period of time. The longer timespan allowed to identify more meaningful permanencies: land uses, road connections and hydraulic artifacts testifying their resilience to historical, social, economic and technical changes. The final output (synchronic map) is more diversified and detailed as the data come from.

Concerning interpretation of landscape as a system, which include tangible and intangible heritage (Branduini, Laviscio, L'Erario, \& Toso, 2019), in the LASHA methodology, long time permanencies may be connected not only to physical aspects and may allow an easy detection of intangible permanencies related to long time developed and consolidated traditions and techniques (as in the case of the water meadow). This is possible thanks to the informations coming from more detailed maps (cadastral maps) and from a close scale (1.2000), so the diversification of data is carried along the whole comparison process. This is not possible in the VASA were the differences between the agricultural practises are not detectable due to the homogenisation of data as also Varotto states (2019). Clearly in the case of tradition and techniques their identification is not directly observable from the maps. However, cross verifying maps, archive sources (as witnesses of the past) and interviews (for the present) is possible to detect intangible values of the area.

For what concern clarity of the changes, the VASA methodology is presenting a large and clear set of land use change maps that allows an immediate comprehension of the main land use changes occurring in between the two periods of analysis (e.g., anthropization, deforestation, river changes, etc.). This map can be generated since the VASA carries out a pairwise comparison: in the case of a multi-epoch analysis like in the LASHA methodology, such visualization cannot be created and it is replaced by the synchronic multi-temporal map. The VASA methodology computes also a historical index, $\mathrm{HI}$, that allows assessing the degree of emergency or the risk of disappearance for each use of the land (Reterurale, 2021).

\subsection{Digital data availability}

The VASA methodology uses material that exists and is accessible throughout the Italian territory. The LaSHA instead uses cadastral maps that change from territory to territory, from region to region. The material does not have the same quality in all Italian areas and is not available with certainty.

Regarding the interpretation of the data, VASA analysis is based on the interpretation of an image which, depending on the quality, reveals more or less information. The choice of a black and white image to define land use should be contradictory, even if GAl images are the very first ones that cover almost the entire Italy country. It should be impossible to identify different kinds of crops. This downside remains also with current land use and images.

While the LaSHA is based on reliable data written in land registers. However, both are seeking integrations, therefore both try to use additional maps, written and oral information and surveys in the field that can enrich and give solidity to the description. A campaign on situ to verify current land use seems necessary to be sure to define the correct kind of crops.

In addition, VASA analysis prefers quantitative index to understand how the landscape changes in years, but some of those as the historical index for example can return unexpected results that do not represent well the real land use modifications. This index does not work for land uses that don't exist in one of the analysis periods. But it should offer good results to understand which kind of crops or lands have a persistence, even if it doesn't express their extensions. At the level of data collected, the LaSHA often presents more in-depth characterization, especially about land uses, having the ability to trace the information transcribed in the land registers.

For the greater amount of data to be tracked, the difficulty of georeferencing, the higher number of information analyzed and the periods studied, the LASHA analysis takes longer. Finally, the VASA analysis has a greater speed of execution due to the use of GIS software to obtain the overlap of the data and implement the required calculations.

\section{Conclusions and future development}

As discussed, the evaluation of landscape integrity is a complex issue due to the identification of key elements and the definition of proper analysis for the evaluation of them. The availability of digital and editable sources is fundamental for any typology of evaluation. More specifically the use of GIS tools is of paramount importance to combine different data sources (e.g., maps, archive information, interviews, etc.) and create a common data infrastructure for any typology of analysis. In addition, GIS tools can be fruitfully used to carry out different typologies of numerical and statistical analysis as well as for creation of maps and visualization of results. In this paper we have compared two different methodologies: VASA and LaSHA. Both of them strongly rely on GIS for analysis and visualization of the results. The comparison showed a complementarity of the two methods: land use change map of VASA methodology can be applied in the LaSHA too when identifying changes in two consecutive epochs. Conversely, when a comparison from different periods is needed, LaSHA synchronic analysis is more suitable, because it allows a quick look to old permanencies thanks to the colour gradient.

Looking at the final users of the methodologies, as the landscape committees, the synchronic map allows them to read and assess easily the main important permanencies in the landscape in order to attribute values and preserve traces and meaning. This investigation can be useful to those who have to manage the transformation of the landscape and preserve the historical characters. It is useful to recognise permanencies and to assess the state of integrity. At the national level, it can be useful for 
the delegates from the Ministry of Cultural heritage (architect and archaeologist) that are in charge of evaluating landscape transformations (in Italy) and to the Municipal and Park landscape Commissions in charge to understand the degree of historical permanencies in the landscape. At an international level, the suitability of the proposed methods is conditioned to the availability of maps of the local territory, it can be useful for evaluating landscape transformation projects in order to recognize material traces and intangible meanings and assess whether the proposed transformations respect or damage them.

The results presented in this work are derived from a first analysis and comparison of the two methods. In our future works we are planning to deepen our study in two directions: i) enlarge the analysis to other municipalities in the nearby of the Ticino river and to different areas characterized by different landscape to understand the flexibility of the two methods at a territorial scale, ii) test the use of both final output map to different end users, in order to check the clarity, ease of understanding and practicality in the everyday evaluation work.

\section{Acknowledgements}

The authors would like to acknowledge Martina Motti Sparacio for grammar check and proofreading.

\section{References}

Agnoletti, M. (2006). The Conservation of Cultural Landscapes. CABI. Cambridge. https://doi.org/10.1079/9781845930745.A

Agnoletti, M. (2007). The degradation of traditional landscape in a mountain area of Tuscany during the $19^{\text {th }}$ and $20^{\text {th }}$ centuries: Implications for biodiversity and sustainable management. Forest Ecology and Management. https://doi.org/10.1016/j.foreco.2007.05.032

Agnoletti, M., \& Tempesta, T. (2016). Linee guida per il dossier di candidatura all'osservatorio nazionale del paesaggio rurale. ISMEA. Retrieved March 15, 2021, from www.reterurale.it

Branduini, P., Laviscio, R., L'Erario, A., \& Toso, F., C. (2019). Mapping evolving historical landscape systems. The International Archives of the Photogrammetry, Remote Sensing and Spatial Information Sciences, Volume XLII2/W11. https://doi.org/10.5194/isprs-archives-XLII-2-W11-277-2019

Brovelli, M.A., \& Minghini, M. (2012). Georeferencing old maps: a polynomial-based approach for Como historical cadastres. e-Perimetron 7(3). 97-110.

Gullino, P., \& Larcher, F. (2013). Integrity in UNESCO World Heritage Sites. A comparative study for rural landscapes. Journal of Cultural Heritage 14, 389-395. https://doi.org/10.1016/j.culher.2012.10.005

ICOMOS. (2017). Principles concerning Rural Landscapes as Heritage. ICOMOS-IFLA. Retrieved March 15, 2021, from https://www.icomos.org/images/DOCUMENTS/Charters/GA2017_6-3-1_RuralLandscapesPrinciples_EN_adopted15122017.pdf

Krakow Charter. (2000). The Krakow Charter. Principles for conservation and restoration of built heritage. The International Conference of Conservation, Krakow

Mitchell, N. (2008). Considering the Authenticity of Cultural Landscapes. APT Bulletin. The Journal of Preservation Technology, 39(2/3), 25-31. Retrieved November 3, 2020 from http://www.jstor.org/stable/25433948

Previtali, M., \& Latre, M., Á. (2018). A brokered Virtual Hub approach for the generation of web applications based on historical maps. Applied Geomatics, 10(4), 453-472. https://doi.org/10.1007/s12518-018-0235-1

Reterurale. 2021. Criteri di ammissibilità e tempistiche per le candidature delle aree nel Registro Nazionale del Paesaggio $\begin{array}{llll}\text { rurale storico. } & \text { Retrieved } 2021, \quad \text { February } & \text { from }\end{array}$ https://www.reterurale.it/flex/cm/pages/ServeBLOB.php/L/IT/IDPagina/13826

Scazzosi, L., \& Branduini, P. (2014). Paesaggio e fabbricati rurali. Suggerimenti per la progettazione e la valutazione paesaggistica, Ministero dei Beni e delle Attività Culturali e del Turismo, Maggioli.

Scazzosi, L. (2004). Reading and assessing the landscape as cultural and historical heritage. Landscape Research, 29, 335-355

Scazzosi, L. (2011). Lombardia. In M. Agnoletti. Paesaggi Rurali Storici. Per un catalogo nazionale/Historical Rural Landscape. For a National Register, 204-206. Laterza.

Scazzosi, L. (2018a). Rural landscape as heritage: Reasons for and implications of 'Principles Concerning Rural Landscapes as Heritage ICOMOS-IFLA 2017'. Built Heritage 2, 39-52. https://doi.org/10.1186/BF03545709

Scazzosi, L. (2018b). Landscape as systems of tangible and intangible relationships. Small theoretical and methodological introduction to read and evaluate Rural Landscape as Heritage. In E. Rosina \& L. Scazzosi (Eds.), The conservation and enhancement of built and landscape heritage, 19-40. PoliScript.

UNESCO. (1972). World Heritage Convention. UNESCO. Retrieved March 15, 2021, from https://whc.unesco.org/archive/convention-en.pdf

Varotto, M. (2019). Oltre la vetrina: i paesaggi rurali storici come strumento per una ruralità sostenibile e multifunzionale 
in Salvatori, F. (2017). L' apporto della geografia tra rivoluzioni e riforme. Programma e abstract. $32^{\circ}$ Congresso geografico italiano (Roma, 7-10 giugno 2017). A. Ge.I. Roma.

Venice Charter. (1964). International Charter for the Conservation and Restoration of Monuments and Sites. The Venice Charter. ICOMOS. Venice

Yang, C., \& Han, F. (2020). A digital information system for cultural landscapes: the case of Slender West Lake scenic area in Yangzhou. China. Built Heritage 4(1). 1-14. https://doi.org/10.1186/s43238-020-00004-8 